\title{
Consumo e digestibilidade dos nutrientes em bovinos alimentados com dietas à base de volumosos tropicais
}

\author{
Luciano da Silva Cabral ${ }^{1}$, Sebastião de Campos Valadares Filho², Edenio Detmann², Pedro \\ Antônio Muniz Malafaia ${ }^{3}$, Joanis Tilemahos Zervoudakis ${ }^{1}$, Alexandre Lima de Souza ${ }^{4}$, Rafael \\ Gonçalves Veloso ${ }^{5}$, Polyana Mary Magalhães Nunes ${ }^{5}$
}

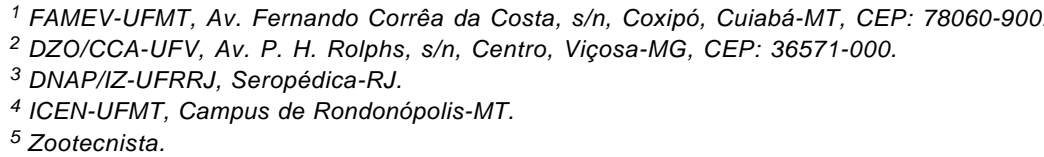

RESUMO - Objetivou-se determinar os consumos de MS, PB, EE, CT, FDN e CNF e as digestibilidades aparentes totais e parciais desses nutrientes em bovinos alimentados com dietas à base de silagens de milho e de capim-elefante e feno de capimTifton 85 . Os volumosos compuseram $90 \%$ da MS das dietas, as quais foram suplementadas com $10 \%$ de farelo de soja Foram utilizados seis bovinos fistulados no rúmen e abomaso (peso inicial de $351 \mathrm{~kg}$ ) em um delineamento em quadrado latino 3 x 3 duplo, simultâneos. Cada período experimental constou de 16 dias, sendo os 10 primeiros destinados à adaptação dos animais e os seis dias restantes para coleta de amostras de fezes e digesta abomasal. Utilizou-se a fibra em detergente neutro indigestível (FDNi) como indicador do fluxo de MS abomasal e fecal. Embora as dietas à base de silagem de milho e de feno de capim-Tifton 85 não tenham diferido quanto à ingestão de MS, a dieta à base de silagem de milho permitiu maior ingestão de NDT. A dieta de feno de capim-Tifton 85 promoveu promoveu maior consumo de FDN (4,52 kg/dia), enquanto aquela com silagem de milho resultou em maior ingestão de CNF $(1,95 \mathrm{~kg} / \mathrm{dia})$. A dieta com silagem de milho proporcionou maior digestibilidade aparente total de MS (66,3\%), MO $(68,9 \%)$, FDN $(55,7 \%)$ e CT $(68,2 \%)$. O rúmen foi o principal local de digestão dos carboidratos totais e da FDN para todas as dietas. Considerando a relação inversa entre a digestibilidade total da matéria seca e a ingestãode FDNi, pode-se inferir que essa última fração pode ser utilizadana estimativa da digestibilidade de gramíneas tropicais. A estimativa da digestão verdadeira dos CNF foi de 96,6\% para as dietas avaliadas.

Palavras-chave: capim-elefante, feno de tifton 85 , ruminantes, silagem de milho, valor nutritivo

\section{Intake and digestibility in cattle fed tropical forage based diets}

\begin{abstract}
The objective of this trial was to investigate the effects of diets containing corn silage, bermudagrass hay, or elephantgrass silage on intake and apparent total tract and partial digestibilities of nutrients in cattle. A forage to concentrate (soybean meal) ratio of 90:10 was used. Six ruminally and omasally fistulated bovines averaging $351 \mathrm{~kg}$ of initialbody weight were used in two replicated 3 x 3 Latin squares. Each experimental period lasted 16 days with 10 days for animal adaptation and six days for samples collection. The internal marker indigestible neutral detergent fiber (INDF) was used to estimate abomasal DM flow and fecal DM excretion. No significant difference in DM intake was observed between corn silage and bermudagrass hay diets. However, total digestible nutrient intake was greater on corn silage than bermudagrass hay. Animals fed the bermudagrass hay diet had the greatest NDF intake $(4.52 \mathrm{~kg} / \mathrm{day})$ while those fed corn silage showed the highest NFC intake $(1.95 \mathrm{~kg} /$ day $)$. In addition, the corn silage diet also resulted in the greatest apparent total tract digestibilities of DM (66.3\%), OM (68.9\%), NDF (55.7\%), and total carbohydrates (68.2\%). Rumen was the main site for digestion of total carbohydrates and NDF in all four diets. It was observed an inverse relationship between apparent total tract DM digestibility and INDF intake. Therefore, forage INDF content can be used to estimate digestibility of tropical grasses. Estimated NFC true digestibility averaged $96.6 \%$ across diets in the present study.
\end{abstract}

Key Words: bermudagrass hay, corn silage, elephantgrass, nutritive value, ruminant

\section{Introdução}

A resposta produtiva dos animais é função do consumo, da digestibilidade e do metabolismo dos nutrientes dietéticos. Destes fatores, o consumo é o mais importante, pois 60 a $90 \%$ da variação observada na ingestão de energia digestível entre animais e dietas está relacionada às diferenças no consumo e somente 10 a $40 \%$, às 
diferenças na digestibilidade (Crampton et al., 1960; Reid, 1961).

Como resultado da falta de habilidade na mensuração do consumo e da separação dos efeitos do animal e da dieta, não se tem atingido melhor entendimento dos fatores básicos que limitam o consumo (Mertens, 1994).

Em ruminantes, fatores fisiológicos, físicos e psicogênicos parecem controlar o consumo (Mertens, 1994). A saciedade seria um fator fisiológico limitante do consumo para dietascom elevada densidade calórica; neste caso, as exigências do animal controlariam o consumo, como em condições de confinamento. Os fatores físicos predominam em dietas de baixa qualidade, em que o consumo é limitado pelo volume ocupado pela dieta e pela capacidade anatômica do rúmen-retículo, de modo que, raramente, os animais ingerem energia suficiente para atender seus requisitos, o que geralmente ocorre com animais em pastejo. Os moduladores psicogênicos referem-se à resposta do animal a fatores estimuladores ou inibidores do alimento ou do ambiente de alimentação, os quais não estão relacionados à concentração de energia do alimento ou à repleção ruminal (Mertens, 1994).

A energia é considerada o principal fator limitante à vida e às funções produtivas e, portanto, sua determinação nos alimentos é de extrema importância para o perfeito atendimento das necessidades nutricionais. A energia nos alimentos pode ser expressa como EB, ED ou NDT e EL. Embora seja a forma mais correta para expressar a energia útil dos alimentos, a determinação da EL é laboriosa e de elevado custo e, por ser a energia perdida nasfezes a maior e mais variável entre todas as perdas de um alimento, é essencial o conhecimento da ED ou do NDT (NRC, 1989; Weiss, 1993; NRC, 1996; NRC, 2001;).

A digestão dos nutrientes dietéticos nos mamíferos ocorre por meio dos processos de hidrólise ácida e enzimática no estômago e intestino e por meio da ação microbiana nos compartimentos fermentativos. Nos ruminantes, a fermentação pré-gástrica permite a eficiente utilização de alimentos fibrosos, entretanto, perdas energéticas e protéicas estão associadas a este processo (Russell et al., 1992).

Considerando que não são digeridos no intestino delgado, é desejável que os constituintes fibrosos sejam fermentados no rúmen, produzindo ácidos graxos voláteis e células microbianas, os quais representam a principal fonte de energia e aminoácidos para o ruminante. Entretanto, alguns fatores podem afetar a digestão ruminal desses compostos, incluindo aqueles relacionados às características físico-químicas da parede celular vegetal, a taxa de passagem da digesta para os intestinos e as variações na microbiota ruminal e nas características físico-químicas do rúmen.

Neste trabalho, foram determinados o consumo e as digestibilidades aparentes total e parcial dos nutrientes em bovinos mestiços alimentados com dietas à base de silagens de milho e capim-elefante e feno de capim-Tifton 85 .

\section{Material e Métodos}

O experimento foi realizado no Laboratório Animal do Departamento de Zootecnia da Universidade Federal de Viçosa-MG, onde foram avaliadas dietas à base de silagem de milho (Zea mays, L.), de feno de capim-tifton 85 (Cynodon spp.) e de silagem de capim-elefante (Pennisettum purpureum, schum), variedade Cameroon, complementadas com $10 \%$ de farelo de soja, constituindo os tratamentos experimentais. Como o feno de capimTifton 85 apresentou apenas $5 \%$ de PB, a dieta baseada neste volumoso foi também suplementada com $0,5 \%$ da mistura uréia:sulfato de amônio (9:1), para tornar as dietas isoprotéicas.As silagens de milho e capim-elefante foram confeccionadas, cada uma, em quatro silos de manilha, com diâmetro de $1 \mathrm{~m}$ e capacidade de $1,5 \mathrm{t}$ de matéria verde.

O milho utilizado para ensilagem (híbrido AG 1051), adquirido junto a um produtor do município de Viçosa MG, foi colhido aos 110 dias após a germinação, quando os grãos atingiram o estádio farináceo-duro. O capim-elefante foi cultivado em área experimental do Departamento de Zootecnia da UFV e cortado aos 120 dias de idade. O capimtifton 85 foi cultivado em área experimental da UFV, no município de Capinópolis - MG, sendo cortado para fenação com aproximadamente 80 dias.

Foram utilizados seis bovinos mestiços com peso vivo médio inicial de $351 \mathrm{~kg}$, fistulados no rúmen e abomaso, segundo técnicas descritas por Leão \& Coelho da Silva (1980). O delineamento experimental utilizado foi em dois quadrados latinos 3 x 3, simultâneos. Cada período experimental teve duração de 16 dias: os dez primeiros para adaptação dos animais às dietas e os seis dias seguintes para coleta de digesta abomasal e de fezes para determinação das digestibilidades aparentes ruminal e total, respectivamente. A digestibilidade aparente pós-ruminal foi medida pela diferença entre as digestibilidades total e ruminal.

Os animais foram pesados antes e após cada período experimental, sendo mantidos estabulados em baias individuais cobertas e com piso de concreto. A dieta foi fornecida uma vez ao dia ( $7 \mathrm{~h} 30)$ e, diariamente, as sobras foram quantificadas para ajuste e determinação do consumo 
voluntário, a fim de proporcionar, aproximadamente, 5\% de sobras na MS.

As coletas de amostras de fezes e da digesta abomasal foram feitas a cada 26 horas, com início às $8 \mathrm{~h}$ do 11 o dia e término às $18 \mathrm{~h}$ do último dia de cada período. As amostras de fezes, de digesta abomasal e as de sobras no cocho foram pré-secas em estufa de ventilação forçada, a $55^{\circ} \mathrm{C}$ durante 72 horas. Posteriormente, as amostras diárias de cada período e tratamento foram misturadas para obtenção das amostras compostas para posteriores análises químicobromatológicas.

Seqüencialmente, as amostras foram processadas em moinho com peneiras de $1 \mathrm{~mm}$ para posterior determinação dos teores de MS, compostos nitrogenados (N), EE, cinzas (Silva \& Queiroz, 2002), FDN e FDN corrigida para cinzas e proteínas (FDNcp) (Van Soest et al., 1991).Foramcalculados os teores dos CT $(\mathrm{CT}=100-(\% \mathrm{~PB}+\% \mathrm{EE}+\%$ cinzas $))$ e dos $\mathrm{CNF}(\mathrm{CNF}=\mathrm{CT}-\mathrm{FDNcp})$ ), de acordo com Sniffen et al. (1992).

Para determinação da excreção de MS fecal e do fluxo de MS abomasal com o objetivo de estimar a digestão total e ruminal dos nutrientes, respectivamente, foi utilizada a FDN indigestível (FDNi) como indicador, determinada in vitro durante 144 horas, conforme Cochram et al. (1986).

O fluxo de MS no abomaso e a excreção fecal (g/animal/ dia) foram estimados pela relação entre a quantidade de indicador consumida (FDNi) nas dietas e sua concentração nas digestas abomasal e fecal, respectivamente. Subtraindo a quantidade de MS que fluiu para o abomaso daquela ingerida, obteve-se a digestão ruminal aparente de MS. Da mesma forma, a digestão aparente total foi obtida pela diferença entre a MS da excreção fecal e o consumo de MS. A digestão pós-ruminal da MS foi estimada pela dedução da digestão ruminal da MS da digestão aparente total. As digestões ruminal e total de cada nutriente (PB, EE, MO, CT, FDN e CNF) foram obtidas pela diferença entre o consumo do nutriente e sua quantidade nas digestas abomasal ou fecal, respectivamente.

O teor de NDT das dietas foi calculado por meio da equação apresentada pelo NRC (2001):

$$
\mathrm{NDT}(\%)=\mathrm{PB}_{\mathrm{D}}+\mathrm{FDN}_{\mathrm{D}}+\mathrm{CNF}_{\mathrm{D}}+\mathrm{EE}_{\mathrm{D}} * 2,25
$$

em que $\mathrm{PB}_{\mathrm{D}}=\mathrm{PB}$ digestível; $\mathrm{FDN}_{\mathrm{D}}=\mathrm{FDN}$ digestível, $\mathrm{CNF}_{\mathrm{D}}=\mathrm{CNF}$ digestíveis; e $\mathrm{EE}_{\mathrm{D}}=\mathrm{EE}$ digestível.

Os dados foram analisados de acordo com o seguinte modelo estatístico:

$$
\mathrm{Y}_{\mathrm{ijkl}}=\mu+\mathrm{Q}_{\mathrm{i}}+\mathrm{T}_{\mathrm{j}}+\mathrm{P}_{\mathrm{k}}+\mathrm{A}_{(\mathrm{i}) \mathrm{l}}+\mathrm{QT}_{\mathrm{ij}}+\mathrm{e}_{\mathrm{ijkl}}
$$

em que: $\mu=$ constante geral; $Q=$ efeito referente ao quadrado latino $\mathrm{i} ; \mathrm{T}_{\mathrm{j}}=$ efeito referente ao tratamento ou à dieta $\mathrm{j} ; \mathrm{P}_{\mathrm{k}}=$ efeito referente à linha ou ao período $\mathrm{k} ; \mathrm{A}_{(\mathrm{i}) \mathrm{l}}=$ efeito de coluna ou animal 1 , aninhado ao quadrado latino $\mathrm{i} ; \mathrm{QT}_{\mathrm{ij}}=$ efeito da interação quadrado latino i $\times$ tratamento $\mathrm{j} ; \mathrm{e}_{\mathrm{ijkl}}=$ erro aleatório, pressuposto erro normalmente e independentemente distribuído (NID) $\left(0, \sigma^{2}\right)$.

$\mathrm{O}$ valor de $\mathrm{F}$ na ANOVA para tratamento foi calculado como a razão entre os quadrados médios para tratamentos e a interação quadrado latinox tratamentos. A comparação entre médias foi realizada por meio do teste Student-NewmanKeulls, adotando-se $\alpha=0,05$.

\section{Resultados e Discussão}

Nas Tabelas 1 e 2 são apresentados os teores médios de PB, EE, cinzas, CT, FDN, CNF e FDNI dos alimentos e das dietas, respectivamente.

$\mathrm{Na}$ Tabela 3 constam os resultados dos consumos médios de MS, MO, PB, EE, CT, FDN, CNF e NDT, expressos

Tabela 1 - Composição químico-bromatológica da silagem de milho (SM), da silagem de capim-elefante (SCE), do feno de capim-tifton 85 (FCT) e do farelo de soja (FS)

Table 1 - Chemical composition of corn silage (CS), elephantgrass silage

\begin{tabular}{|c|c|c|c|c|}
\hline \multirow[t]{2}{*}{$\begin{array}{l}\text { Item } \\
\text { Item }\end{array}$} & \multicolumn{4}{|c|}{$\begin{array}{c}\text { Dieta } \\
\text { Diet }\end{array}$} \\
\hline & $\begin{array}{l}\text { SM } \\
C S\end{array}$ & $\begin{array}{c}\text { SCE } \\
E S\end{array}$ & $\begin{array}{c}\text { FCT } \\
B H\end{array}$ & $\begin{array}{c}\text { FS } \\
S M\end{array}$ \\
\hline $\operatorname{MS}(\%)(D M)$ & 25,65 & 18,34 & 86,00 & 88,00 \\
\hline $\mathrm{PB}^{1}(C P)$ & 7,31 & 6,53 & 5,00 & 47,58 \\
\hline Cinzas $^{1}($ Ash) & 5,79 & 11,18 & 6,83 & 5,84 \\
\hline $\mathrm{EE}^{1}(E E)$ & 2,49 & 1,52 & 1,37 & 1,52 \\
\hline $\mathrm{CT}^{1}(T C)$ & 84,40 & 80,76 & 86,80 & 45,05 \\
\hline $\mathrm{FDN}^{1}(N D F)$ & 56,58 & 75,42 & 87,63 & 11,57 \\
\hline $\operatorname{FDNcp}^{1}(N D F a p)$ & 53,14 & 68,86 & 80,70 & 10,92 \\
\hline $\mathrm{CNF}^{1}(N F C)$ & 31,27 & 11,90 & 6,09 & 34,13 \\
\hline $\mathrm{FDNI}^{1}(I N D F)$ & 19,45 & 27,10 & 36,26 & 3,32 \\
\hline
\end{tabular}
$(E S)$, bermudagrass hay $(B H)$ and soybean meal (SM)

$1 \%$ na MS $(\%$ of $D M)$

Tabela 2 - Composição químico-bromatológica das dietas à base de silagem de milho (SM), silagem de capim-elefante (SCE) e feno de capim-tifton 85 (FCT)

Table 2 - Chemical composition of corn silage (CS), elephantgrass silage

\begin{tabular}{|c|c|c|c|}
\hline \multirow[t]{2}{*}{$\begin{array}{l}\text { Item } \\
\text { Item }\end{array}$} & \multicolumn{3}{|c|}{$\begin{array}{c}\text { Dieta } \\
\text { Diet }\end{array}$} \\
\hline & $\begin{array}{l}\text { SM } \\
C S\end{array}$ & $\begin{array}{c}\text { SCE } \\
E S\end{array}$ & $\begin{array}{c}\mathrm{FCT} \\
B H\end{array}$ \\
\hline $\mathrm{PB}^{1}(C P)$ & 11,33 & 10,63 & 10,66 \\
\hline $\operatorname{Cinzas}^{1}(A s h)$ & 5,79 & 10,65 & 6,73 \\
\hline $\mathrm{EE}^{1}$ & 2,39 & 1,52 & 1,38 \\
\hline $\mathrm{CT}^{1}(T C)$ & 80,47 & 71,20 & 82,63 \\
\hline $\mathrm{FDN}^{1}(N D F)$ & 52,08 & 69,03 & 80,02 \\
\hline $\operatorname{FDNcp}^{1}$ (NDFap) & 48,92 & 63,07 & 73,72 \\
\hline $\mathrm{CNF}^{1}(N F C)$ & 31,56 & 14,13 & 8,90 \\
\hline $\mathrm{FDNI}^{1}(I N D F)$ & 17,43 & 29,43 & 35,40 \\
\hline
\end{tabular}
(ES), and bermudagrass hay (BH)

$1 \%$ na MS (\% of $D M)$ 
Tabela 3 - Resultados médios dos consumos dos nutrientes para as dietas à base de silagem de milho (SM), silagem de capim-elefante (SCE) e feno de capim-Tifton 85

Table 3 - Average intake of nutrients observed for the diets containing corn silage (CS), elephantgrass silage (ES) and bermudagrass hay $(B H)$

\begin{tabular}{lcccc}
\hline Consumo & \multicolumn{3}{c}{ Dieta } & CV (\%) \\
Intake & \multicolumn{3}{c}{ Diet } \\
\cline { 2 - 4 } & $\mathrm{SM}$ & $\mathrm{SCE}$ & FCT \\
& $C S$ & $E S$ & $B H$ \\
\hline
\end{tabular}

$\mathrm{kg} / \mathrm{dia}(\mathrm{kg} /$ day $)$

$\begin{array}{lllll}\text { MS }(D M) & 6,32^{\mathrm{a}} & 4,48^{\mathrm{b}} & 5,75^{\mathrm{a}} & 17,10 \\ \text { MO }(O M) & 5,96^{\mathrm{a}} & 4,02^{\mathrm{b}} & 5,35^{\mathrm{a}} & 17,50 \\ \mathrm{~PB}(C P) & 0,76^{\mathrm{a}} & 0,53^{\mathrm{b}} & 0,69^{\mathrm{a}} & 13,16 \\ \text { EE } & 0,163^{\mathrm{a}} & 0,071^{\mathrm{b}} & 0,067^{\mathrm{b}} & 19,18 \\ \text { CT }(T C) & 5,08^{\mathrm{a}} & 3,44^{\mathrm{b}} & 4,70^{\mathrm{a}} & 18,39 \\ \text { FDN }(N D F) & 3,25^{\mathrm{b}} & 3,04^{\mathrm{b}} & 4,52^{\mathrm{a}} & 18,22 \\ \text { CNF }(N F C) & 1,95^{\mathrm{a}} & 0,71^{\mathrm{b}} & 0,54^{\mathrm{b}} & 22,36 \\ \text { NDT }(T D N) & 4,34^{\mathrm{a}} & 2,49^{\mathrm{b}} & 3,04^{\mathrm{b}} & 19,34\end{array}$

$\mathrm{g} / \mathrm{kg} \mathrm{PV}(\mathrm{g} / \mathrm{kg} B W)$

$\begin{array}{lrrrr}\text { MS }(D M) & 18,17^{\mathrm{a}} & 12,72^{\mathrm{b}} & 16,43^{\mathrm{a}} & 16,63 \\ \text { FDN }(N D F) & 9,33^{\mathrm{b}} & 8,61^{\mathrm{b}} & 12,92^{\mathrm{a}} & 18,82\end{array}$

Valores seguidos com letras sobrescritas diferentes na mesma linha diferem $(P<0,05)$ pelo teste SNK.

Means followed by different superscripts in the same row differ $(P<0.05)$ by SNK test.

$1 \%$ na MS ( $\%$ of $D M)$.

CV \% = coeficiente de variação (coefficient of variation).

em kg por dia, e os consumos de MS e FDN, em g/kg de PV. As dietas à base de silagem de milho e feno de capim-tifton 85 , em comparação àquelas à base de silagem de capim-elefante, proporcionaram maiores consumos de $\mathrm{MS}(\mathrm{kg} / \mathrm{dia})(\mathrm{P}<0,05)$, $\mathrm{MO}, \mathrm{PB}$ e CT.

Embora as dietas à base de silagem de milho e de feno de capim-tifton 85 não tenham diferido quanto ao consum de MS ( $\mathrm{P}>0,05)$, a de silagem de milho propiciou maior consumo $(\mathrm{P}<0,05)$ de NDT ( $43 \%$ maior) quando comparada àquela com feno de capim-tifton 85 , provavelmente em razão do elevado teor de FDN da dieta com feno, a qual influenciou negativamente a disponibilidade dos nutrientes, como resultado de sua lenta e incompleta digestão no trato gastrintestinal (Van Soest, 1967), bem como do elevado teor de FDNi.

Como consequiência do maior teor de FDN, o consumo desta fração foi superior $(\mathrm{P}<0,05)$ para a dieta à base de feno de capim-tifton 85. Considerando que o teor de FDN tem sido negativamente correlacionado ao consumo, quando a repleção é o fator limitante seria esperado maior consumo de MS para a dieta à base de silagem de milho, pois esta dieta apresentou $35 \%$ menos de FDN e quatro vezes mais de CNF que aquela à base de feno de capim-tifton 85. Desta forma, pode-se inferir que o consumo da dieta à base de silagem de milho foi controlado por fatores fisiológicos ou pela elevada concentração de ácidos orgânicos, decorrentes da fermentação dos seus açúcares solúveis.

Mertens (1994) observou que a ingestão de MS foi maximizada quando a ingestão de FDN foi de $12,5 \mathrm{~g} / \mathrm{kg}$ de $\mathrm{PV}$ e que, acima deste valor, a repleção ruminal limitaria o consumo. Desta forma, pode-se sugerir que, para a dieta à base de feno de capim-tifton 85 , o consumo foi limitado pelo enchimento ruminal. De acordo com a proposição de Mertens (1987), o consumo da dieta à base de silagem de milho seria controlado pela demanda energética dos animais ou pelos moduladores psicogênicos (Mertens, 1987; Mertens, 1994). Como o teor de CNF foi elevado e o teor de FDN da silagem de milho foi baixo, provavelmente sua ingestão foi controlada por fatores fisiológicos, ou seja, pelas exigências energéticas do animal.

Embora a dieta à base de silagem de capim-elefante tenha proporcionado menores teores de FDN e FDNi que a dieta à base de feno de capim-tifton 85 , o consumo de MS foi inferior $(\mathrm{P}<0,05)$ ao da dieta à base de silagem de capimelefante. Esse resultado pode ser explicado pelo fato de se tratar de silagem de capim, que, em decorrência de fermentações indesejáveis, culminaria com sabor e odores desagradáveis, afetando de forma negativa o consumo de MS (Van Soest, 1994). Embora não tenha sido mensurada a presença de produtos finais da fermentação que pudessem conferir odor desagradável à silagem de capim-elefante, como o ácido butírico e o nitrogênio amoniacal $\left(\mathrm{N}-\mathrm{NH}_{3}\right)$, tanto a cor quanto o odor verificados na silagem permitem inferir a ocorrência desse problema.

Como resultado do maior teor em CNF e EE na dieta à base de SM, o consumo destes nutrientes foi superior $(\mathrm{P}<0,05)$ ao das dietas à base de feno e silagem de capimelefante.

Conforme demonstrado na Tabela 4 , a dieta à base de silagem de milho apresentou maior digestão total $(\mathrm{P}<0,05)$ da MS, MO e dos CT que as dietas à base de feno de capimtifton 85 e silagem de capim-elefante. Esse resultado pode ser atribuído ao elevado teor de CNF deste volumoso, uma vez que estes carboidratos apresentam digestibilidade rápida e praticamente completa no trato gastrintestinal (TGI) dos ruminantes. Ao contrário, os carboidratos fibrosos (CF), presentes em elevada concentração no feno de capimtifton 85 e na silagem de capim-elefante, apresentam digestibilidade lenta e incompleta e, portanto, consistem na principal fonte de variação na digestibilidade de forrageiras (Van Soest, 1967; Mertens, 1994).

Adicionalmente, o elevado teor de FDNi do feno de capim-tifton 85 e da silagem de capim-elefante pode ter 
Tabela 4 - Resultados médios das digestibilidades aparentes totais e parciais dos nutrientes para as dietas à base de silagem de milho (SM), silagem de capim-elefante (SCE) e feno de tifton 85 (FCT)

Table 4 - Average apparent total tract and ruminal digestibility of nutrients observed for diets containing corn silage (CS), elephantgrass silage (ES), and bermudagrass hay $(B H)$

\begin{tabular}{|c|c|c|c|c|}
\hline \multirow[t]{3}{*}{$\begin{array}{l}\text { Item } \\
\text { ITEM }\end{array}$} & \multicolumn{3}{|c|}{$\begin{array}{l}\text { Dieta } \\
\text { Diet }\end{array}$} & CV $(\%)$ \\
\hline & SM & SCE & FCT & \\
\hline & $C S$ & $E S$ & $B H$ & \\
\hline
\end{tabular}

Digestibilidade total aparente $(\%)$

Apparent total tract digestibility

\begin{tabular}{llllc} 
MS $(D M)$ & $66,28^{\mathrm{a}}$ & $53,23^{\mathrm{b}}$ & $49,89^{\mathrm{b}}$ & 5,90 \\
MO $(O M)$ & $68,91^{\mathrm{a}}$ & $55,24^{\mathrm{b}}$ & $51,27^{\mathrm{b}}$ & 5,52 \\
PB $(C P)$ & $71,88^{\mathrm{a}}$ & $72,89^{\mathrm{a}}$ & $73,45^{\mathrm{a}}$ & - \\
EE & $85,18^{\mathrm{a}}$ & $67,42^{\mathrm{b}}$ & $57,88^{\mathrm{c}}$ & 8,82 \\
CT $(T C)$ & $68,15^{\mathrm{a}}$ & $52,59^{\mathrm{b}}$ & $49,21^{\mathrm{b}}$ & 6,02 \\
FDN $(N D F)$ & $55,70^{\mathrm{a}}$ & $49,52^{\mathrm{b}}$ & $50,76^{\mathrm{b}}$ & 7,51 \\
CNF $(N F C)$ & $85,58^{\mathrm{a}}$ & $65,96^{\mathrm{b}}$ & $41,86^{\mathrm{c}}$ & 15,79 \\
\hline
\end{tabular}

Digestibilidade ruminal

Ruminal digestibility

\begin{tabular}{lcccc}
$\mathrm{MS}^{1}(D M)$ & $62,30^{\mathrm{a}}$ & $57,72^{\mathrm{a}}$ & $53,78^{\mathrm{a}}$ & 12,07 \\
$\mathrm{MO}^{1}(O M)$ & $73,08^{\mathrm{a}}$ & $72,70^{\mathrm{a}}$ & $65,67^{\mathrm{a}}$ & 9,31 \\
$\mathrm{~PB}^{2}(C P)$ & $3,96^{\mathrm{a}}$ & $14,17^{\mathrm{a}}$ & $14,94^{\mathrm{a}}$ & - \\
$\mathrm{CT}^{1}(T C)$ & $89,73^{\mathrm{ab}}$ & $98,05^{\mathrm{a}}$ & $85,88^{\mathrm{b}}$ & 7,11 \\
$\mathrm{FDN}^{1}$ & $87,03^{\mathrm{a}}$ & $95,64^{\mathrm{a}}$ & $87,62^{\mathrm{a}}$ & 6,55 \\
\hline
\end{tabular}

Digestibilidade pós-ruminal

Post-ruminal digestibility

\begin{tabular}{llrll}
$\mathrm{MS}^{1}(D M)$ & $37,70^{\mathrm{a}}$ & $42,28^{\mathrm{a}}$ & $46,21^{\mathrm{a}}$ & 16,63 \\
$\mathrm{MO}^{1}(O M)$ & $26,92^{\mathrm{a}}$ & $27,30^{\mathrm{a}}$ & $34,33^{\mathrm{a}}$ & 22,22 \\
$\mathrm{~PB}^{2}(C P)$ & $96,03^{\mathrm{a}}$ & $85,83^{\mathrm{a}}$ & $85,07^{\mathrm{a}}$ & 24,04 \\
$\mathrm{CT}^{1}(T C)$ & $10,27^{\mathrm{ab}}$ & $1,95^{\mathrm{b}}$ & $14,12^{\mathrm{a}}$ & 73,85 \\
$\mathrm{FDN}^{1}(N D F)$ & $12,97^{\mathrm{a}}$ & $4,36^{\mathrm{a}}$ & $12,38^{\mathrm{a}}$ & 59,00 \\
\hline
\end{tabular}

$1 \%$ do total digerido.

${ }^{2}$ Expresso em \% da quantidade que chegou no local.

Valores seguidos com letras sobrescritas diferentes na mesma linha diferem $(\mathrm{P}<0,05)$ pelo teste SNK.

$1 \%$ the total digestion.

${ }^{2}$ Expressed as \% of the amount present in the segment of the gastrointestinal tract.

Means followed by different superscripts in same row differ $(P<0.05)$ by SNK test.

contribuído para a redução na digestibilidade destes alimentos em relação à silagem de milho, pois, considerando que a FDNi é indisponível tanto no rúmen como nos intestinos, sua concentração nos alimentos pode ser inversamente relacionada à digestibilidade (Figura 1). Como esta fração deixa o rúmen somente por meio do processo de passagem, espera-se grande contribuição para o efeito de repleção ruminal (Vieira et al., 1997).

Ribeiro et al. (2001) observaram consumos de MS para dietas à base de feno de capim-tifton 85 com 28 a 56 dias de rebrota próximos aos observados neste estudo, que variaram de 5,39 a 5,85 kg/dia. Entretanto, a digestibilidade aparente total da MS apresentou valor médio de 70,9\%, bem superior ao observado neste estudo. Embora esses autores tenham trabalhado com maior proporção de concentrado

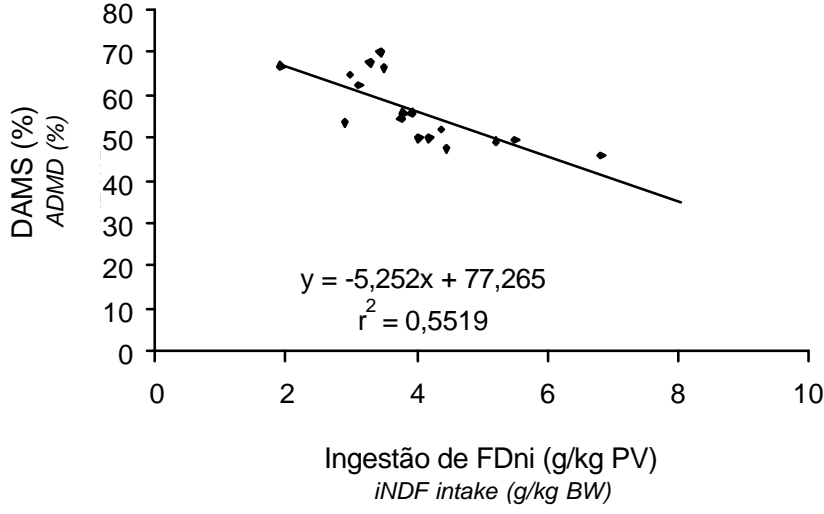

Figura 1 - Estimativa da digestibilidade aparente total da matéria seca (DAMS), em função da ingestão de FDNI ( $\mathrm{g} / \mathrm{kg}$ de PV).

Figure 1 - Estimation of apparent total tract dry matter digestibility $(A D M D)$ in function of INDF intake ( $\mathrm{g} / \mathrm{kg}$ of $B W)$.

(40\%) nas dietas, as diferenças na digestibilidade da MS podem ser atribuídas ao melhor valor nutritivo dos fenos, evidenciado pelos menores teores de FDN (média =79,67\%) e pelos maiores teores de PB (média $=14,37 \%$ ), reflexos da idade de corte na confecção do feno.

A digestibilidade aparente dos CNF foi maior para a silagem de milho, seguida da silagem de capim-elefante e do feno de capim-tifton 85. Os valores para o feno de capim-tifton 85 e para a silagem de capim-elefante foram inferiores aos relatados na literatura (Van Soest, 1967), pois os CNF apresentaram digestibilidade praticamente completa no trato gastrintestinal dos ruminantes (média de $98 \%$ ).

Van Soest (1967), pelo teste da uniformidade nutricional (Lucas et al., 1961, citados por Van Soest, 1967), que determina se as frações químicas dos alimentos permanecem constantes em diferentes espécies de forragens, estabeleceu a regressão entre a quantidade digestível (coeficiente de digestibilidade $\times$ concentração na forragem) do conteúdo celular e sua porcentagem na MS da forragem. Da equação de regressão, o coeficiente angular representa a digestibilidade verdadeira média, enquanto o intercepto corresponde à excreção endógena do componente. Em seu trabalho, Van Soest (1967) encontrou para o conteúdo celular a equação $\mathrm{Y}=-12,9+0,98 \mathrm{X}$, ou seja, esta fração apresenta digestibilidade verdadeira média de $98 \%$ e excreção endógena média de $12,9 \%$ da MS ingerida.

O coeficiente de $98 \%$ para a digestibilidade verdadeira do conteúdo celular encontrado por Van Soest (1967) está de acordo com a observação de Jarrige (1967), citado por Van Soest (1967), de que as fezes dos ruminantes são isentas de carboidratos solúveis. Desta forma, concluiu-se 
que o conteúdo celular das forragens não possui identidade química com o correspondente material solúvel das fezes. Portanto, a digestibilidade aparente dos compostos nitrogenados e do conteúdo celular é função da sua concentração na forragem ou na dieta, relativo à sua produção endógena, o que está de acordo com os coeficientes de digestão aparentes obtidas neste estudo.

Com o intuito de estimar a digestibilidade verdadeira e a excreção endógena dos CNF, semelhantemente ao relatado por Van Soest (1967), foi feita regressão entre a quantidade digestível dos CNF (conteúdo na dieta x coeficiente de digestão) e a porcentagem destes compostos nas dietas (Figura 2). O coeficiente angular da regressão obtido foi de 1,02, próximo ao valor 0,98 verificado por Van Soest (1967), indicando que a digestibilidade verdadeira destes compostos é praticamente completa e, intercepto de $-5,27$, correspondente à excreção metabólica dos CNF. Quando este valor de $-5,27$ relativo à excreção metabólica dos CNF foi subtraído dos CNF fecais, obteve-se o valor de digestão verdadeira média de $96,6 \%$.

A digestibilidade aparente total da MS e MO para a silagem de milho foi próxima aos valores de 68 e $66 \%$ observados por Mora et al. (1996).

Em decorrência da maior digestão aparente total da MS, a dieta à base de silagem de milho apresentou maior teor de NDT que as dietas à base de feno de capim-tifton 85 e silagem de capim-elefante, cujos valores foram 69,$1 ; 52,4 \mathrm{e}$ $55,5 \%$, respectivamente.

Embora não tenha havido diferença estatística entre as dietas quanto à digestão ruminal da MS e da MO, observou-se diferença numérica em favor da silagem de milho. Como a digestão da FDN no rúmen não diferiu entre as dietas, atribuiu-se aos CNF a contribuição para o aumento da digestão ruminal dos nutrientes para dieta à base de silagem de milho, o que implica, provavelmente, em aumento das exigências de proteína degradada no rúmen (PDR) para o atendimento das exigências em compostos nitrogenados $(\mathrm{N})$ dos microrganismos fermentadores destes carboidratos (Russell et al., 1992). Valadares Filho et al. (1985), embora tenham encontrado digestibilidade aparente total da MS ligeiramente superior (71\%) para dietas à base de silagem de milho que a observada neste estudo, obtiveram coeficiente de digestão ruminal similar $(62,75 \%)$.

Para todas as dietas, pelo menos $85 \%$ dos CT e da FDN foram digeridos no rúmen.Para as dietas à base de silagem de capim-elefante e de feno de capim-Tifton 85, nas quais a maior parte dos CT foi representada pela FDN, sua digestão no rúmené altamente desejada, tendo em vista a evolução dos ruminantes para eficiente utilização destes carboidratos, bem como o não aproveitamento da proteína

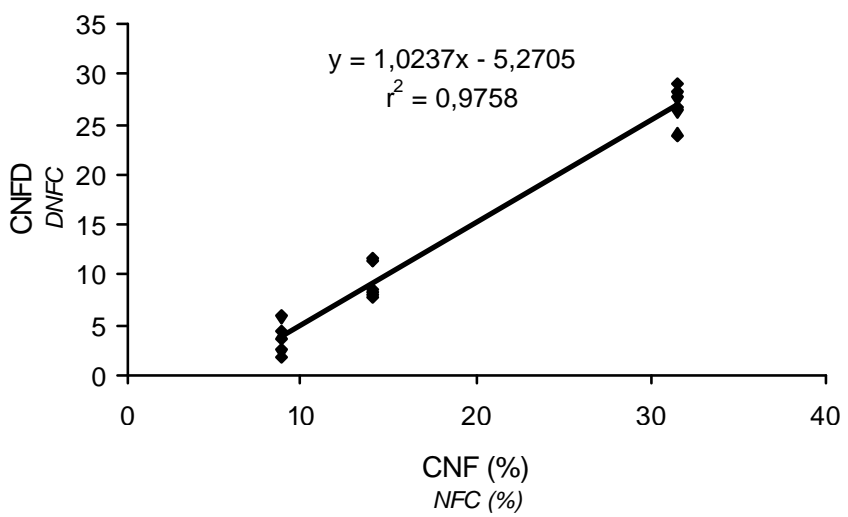

Figura 2 - Estimativa da quantidade digestível dos CNF (CNFD, em \%) em função de sua porcentagem na MS das dietas.

Figure 2 - Estimation of the amount of digestible NFC (DNFC) in function of its dietary dry matter content.

microbiana gerada a partir de sua digestão no intestino grosso. Entretanto, a digestão elevada dos CNF provenientes da silagem de milho no rúmen seria energeticamente menos eficiente, uma vez que a digestão do amido no intestino delgado reduziria as perdas decorrentes de sua fermentação no rúmen. Entretanto, a digestão dos CNF no rúmen pode ser extremamente desejável quando a maior parte da energia destes compostos é retida pelos microrganismos ruminais e utilizada para o crescimento, uma vez que a proteína microbiana constitui importante fonte de aminoácidos nos intestinos dos ruminantes.

\section{Conclusões}

A dieta à base de silagem de milho promoveu maior consumo de nutrientes digestíveis totais.

O principal local de digestão dos carboidratos totais e da FDN foi o rúmen-retículo.

Estimou-se digestibilidade verdadeira de $96,6 \%$ para os carboidratos não-fibrosos.

\section{Literatura Citada}

COCHRAN, R.C.; ADAMS, D.C.; WALLACE, J.D. et al. Predicting digestibility of different diets with internal markers: evaluation of four potential markers. Journal of Animal Science, v.63, n.5, p.1476-1483, 1986.

CRAMPTON, E.W.; DONEFER, E.; LLOYD, L.E. A nutritive value index for forages. Journal of Animal Science, v.19, n.3, p.538-544, 1960.

LEÃO, M.I.; COELHO DA SILVA, J.F. Técnica de fistulação de abomaso em bezerros. In: CONGRESSO BRASILEIRO DE ZOOTECNIA, 1., REUNIÃO ANUAL DA SOCIEDADE BRASILEIRA DE ZOOTECNIA, 17., 1980, Fortaleza.Anais... Fortaleza: Sociedade Brasileiro de Zootecnia, 1980. p.37. 
MERTENS, D.R. Predicting intake and digestibility using mathematical models of ruminal function. Journal of Animal Science, v.64, n.5, p.1548-1558, 1987.

MERTENS, D.R. Regulation of forage intake. In: FORAGE QUALITY, EVALUATION, AND UTILIZATION, 1994, Wisconsin. Proceedings... Wisconsin: 1994. p.450-493.

MORA, P.J.G.; VALADARES FILHO, S.C.; LEÃO, M.I. et al. Digestibilidade aparente dos nutrients e energia líquida da silagem de milho (Zea mays L.) para vacas lactantes. Revista Brasileira de Zootecnia, v.25, n.2, p.357-368, 1996.

NATIONAL RESEARCH COUNCIL - NRC. Nutrient requirements of dairy cattle. 6.ed. Washington, D.C.: National Academy Press, 1989. 158p.

NATIONAL RESEARCH COUNCIL - NRC. Nutrient requirements of beef cattle. 7.ed. Washington, D.C.: National Academy Press, 1996. 242p.

NATIONAL RESEARCH COUNCIL - NRC. Nutrients requirements of dairy cattle. 7.ed. Washington, D.C.: National Academy Press, 2001. 381p.

REID, J.T. Problems of feed evaluation related to feeding dairy cows. Journal of Dairy Science, v.11, n.7, p.2122-2133, 1961.

RIBEIRO, K.G.; GARCIA, R.; PEREIRA, O.G. et al. Consumo e digestibilidades aparentes total e parcial, de nutrientes, em bovinos recebendo rações contendo feno de capim-tifton 85 de diferentes idades de rebrota. Revista Brasileira de Zootecnia, v.30, n.2, p.573-580, 2001.

RUSSELL, J.B.; O'CONNOR, J.D.; FOX, D.G. et al. A net carbohydrate and protein system for evaluation cattle diets: ruminal fermentation. Journal of Animal Science, v.70, n.12, p.3551-3581, 1992.

SILVA, D.J.; QUEIROZ, A.C. Análise de alimentos: métodos químicos e biológicos. 3.ed. Viçosa, MG: Editora UFV, 2002. $235 \mathrm{p}$.
SNIFFEN, C.J.; O'CONNOR, D.J.; Van SOEST, P.J. et al. A net carbohydrate and protein system for evaluating cattle diets: carbohydrate and protein availability. Journal of Animal Science, v.70, n.12, p.3562-3577, 1992.

VALADARES FILHO, S.C.; COELHO DA SILVA, J.F.; LEÃO, M.I. et al. Digestão total e parcial da matéria seca e carboidratos em bovídeos alimentados com duas proporções de volumoso:concentrado (60:40 e 40:60). 3 - Silagem de mMilho. Revista Brasileira de Zootecnia, v. 14, n.5, p.599-609, 1985.

Van SOEST, P.J. Development of a comprehensive system of feeds analysis and its applications to forages. Journal of Animal Science, v.26, n.1, p.119-128, 1967.

Van SOEST, P.J.; ROBERTSON, J.B.; LEWIS, B.A. Methods for dietary fiber, neutral detergent fiber, and nonstarch polyssacarides in relation to animal nutrition. Journal of Dairy Science, v.74, n.10, p.3583-3597, 1991.

Van SOEST, P.J. Nutritional ecology of the ruminant. 2.ed. Ithaca: Cornell University Press, 1994, 476p.

VIEIRA, R.A.M.; PEREIRA, J.C.; MALAFAIA, P.A.M. et al. The influence of elephant-grass (Pennisetum purpureum., Mineiro variety) growth on the nutrient kinetics in the rumen. Animal Feed Science and Technology, v.67, n.23, p.151-161, 1997.

WEISS, P.W. Symposium: prevailing concepts in energy utilization by ruminants. Predicting energy values of feeds. Journal of Dairy Science, v.76, n.6, p.1802-1811, 1993. 